Original Research Paper

\title{
Cracking of Reinforced Recycled Concrete Slabs
}

\author{
Flavio Stochino, Luisa Pani, Lorena Francesconi and Fausto Mistretta
}

Department of Civil, Environmental Engineering and Architecture, University of Cagliari, Cagliari, Italy

Corresponding Author:

Flavio Stochino

Department of Civil,

Environmental Engineering and

Architecture, University of

Cagliari, Cagliari, Italy

Email: fstochino@unica.it

\begin{abstract}
The results of an experimental investigation on cracking of fifteen reinforced recycled concrete slabs are presented in this paper. Five different recycled aggregates replacement percentages have been used for different mix design. First, the values of tensile strength, cylindrical compressive strength and modulus of elasticity of the concrete mixes have been determined. Then the deflection-load curve of the simply supported slabs have been obtained. The limit of the linear part of this curve determines the experimental cracking load. Its comparison with the theoretical value shows good agreement. Recycled concrete slabs show a similar performance to those made with ordinary concrete.
\end{abstract}

Keywords: Slab, Recycled Concrete Aggregate, Recycled Concrete Cracking

\section{Introduction}

Concrete is a wide adopted building material. Its behavior under ordinary and extreme conditions, see Acito et al. (2011), Stochino (2016), Stochino et al. (2017), is a current and relevant topic. Likewise, the use of natural aggregates for its production presents an important problem for sustainable development (Etxeberria et al. (2007)). Indeed, it is necessary to exploit a quarry or to open a new mining site for the natural aggregate production and this has a strong impact on the territory.

The construction world, on the other hand, produces a huge amount of waste materials. The European Guidelines (European Parliament (2011)) encourage the use of recycled materials for the development of new products. Many researchers have focused their studies on the use of recycled aggregates obtained from the construction demolition waste in the production of new recycled concrete (Francesconi et al. (2016), Mália et al. (2013), Levy and Helene (2004), Hansen and Narud (1983), Li (2008; 2009)). Indeed, the use of construction wastes reduces the exploitation of soil and subsoil and extend the service life of quarries and mines, delaying the opening of new mining sites and thus preserving non-recoverable natural resources.

The benefits of using recycled aggregates for concrete production are clear. The use of natural aggregates can be limited and the material placed in landfills could be significantly reduced, with remarkable twofold advantage for the environment.
Many researches (Rahal (2007), De Brito et al. (2016), Evangelista and De Brito (2007), Poon et al. (2004)) investigated the effects of recycled aggregates obtained from concrete demolition waste on the performance of the new concrete. They have shown that these recycled aggregates have different properties compared to natural ones (high absorption value, lower density and higher Los Angeles value). Moreover, since the original concrete used for their production can have very different properties, the recycled aggregates present dispersion in mechanical performance. For this reason, even today the use of recycled aggregates for the production of structural concrete is seen with suspicion. Many countries in the world have defined Codes, Recommendations and Guidelines for the use of Recycled Concrete Aggregates (ACI 555 (2001), Collins (1998), BS 6543 (1985), DIN 4226-100 (2002), NTC (2008), Model Code (2010), ACI 318 (2011)).

Actually, many studies have been also carried out on the performance of reinforced concrete recycled beams and pillars (Pacheco et al. (2015), Gonzalez-Fonteboa and Martinez-Abella (2007), Yang and Han (2006), but still limited in relation to slabs behavior (Francesconi et al. (2006), Reis et al. (2015)).

The reinforced concrete slabs have various design advantages in comparison with other horizontal floor: thickness reduction, simplicity of casting, flexibility in spaces division. Thus, it can be considered an economical and efficient structural system. Although apparently simple, its structural behavior may be quite 
complex. In particular, the punching mechanism is very dangerous because of its fragile nature and because it may be a source of a collapse.

First theoretical models for slab punching were based on the theoretical mechanics. Unfortunately, the design formulas obtained from these models were quite complicated and not efficient for practical use. Many researchers have tried to produce reliable and simple design expressions that have been included in the major international codes (Model Code (2010), Eurocode 2 (2008) (EC2), ACI 318 (2011)).

In this work, in order to better understand the behavior of recycled reinforced concrete slabs, new experimental data on first cracking are presented. About 15 slabs were made with different mixtures of recycled concrete. The mixtures are divided into 5 groups considering different replacement percentage of recycled aggregates in place of natural aggregates: $0 \%, 30 \%$, $50 \%, 80 \%$ and $100 \%$. Slabs dimensions were $1100 \times 1100 \times 50 \mathrm{~mm}$. A low reinforcement ratio $(\rho=$ $0.56 \%$ ) were adopted. The slabs were simply supported and subjected to a central patch distributed over a $200 \times 200 \mathrm{~mm}$ area. The experimental cracking load has been compared to the theoretical one in order to analyze the structural performance of slabs made with the recycled aggregates produced by concrete waste of unknown mechanical properties and state of conservation. In fact, recycled aggregates used in the current experimental campaign were randomly taken from three authorized storage sites operating in southern Sardinia. More details can be found in Francesconi et al. (2016).

\section{Materials}

Cement CEM II/A-LL 42.5 R with locally available fine and large natural and recycled aggregates have been used. In all mixtures, a super-fluidizing additive was used, consequently the consistency class was greater than or equal to S4. A double B450A steel squared $(100 \times 100$ $\mathrm{mm}$ - dimater $5 \mathrm{~mm}$ ) welded mesh represented the slab reinforcement. Concrete cover thickness was $10 \mathrm{~mm}$.

Table 1 presents the main properties of natural and recycled aggregates (density $\rho$, density on dry surface $\rho_{\text {ssd }}$, water absorption WA24).

Table 2 shows the composition of concrete mixtures.

The mixes are divided into 5 groups considering the replacement percentage (Rep \%).

In order to test the concrete mechanical characteristics $\left(f_{c}\right.$ compressive cylindrical strength, $f_{c t}$ tensile strength, Yoing's modulus $E_{c}$ ), three cylindrical samples $(150 \mathrm{~mm}$ diameter, $300 \mathrm{~mm}$ height $)$ were prepared from each mixture, see Table 3.
Table 1. Properties of natural and recycled aggregates

\begin{tabular}{lllll}
\hline Aggregates & $\begin{array}{l}\text { Dimension } \\
(\mathrm{mm})\end{array}$ & $\begin{array}{l}\rho \\
\left(\mathrm{kg} / \mathrm{m}^{3}\right)\end{array}$ & $\begin{array}{l}\rho_{\text {ssd }} \\
\left(\mathrm{kg} / \mathrm{m}^{3}\right)\end{array}$ & $\begin{array}{l}\mathrm{WA}_{24} \\
(\%)\end{array}$ \\
\hline Fine natural & $0-4$ & 2707 & 2630 & 2.00 \\
Coarse Natural & $4-12$ & 2691 & 2600 & 1.40 \\
Coarse Recycled & $4-12$ & 2630 & 2360 & 7.54 \\
\hline
\end{tabular}

Table 2. Concrete mix

\begin{tabular}{llllll}
\hline & $\begin{array}{c}\text { Rep } \\
(\%)\end{array}$ & $\begin{array}{c}\text { Cem } \\
(\mathrm{kg})\end{array}$ & $\begin{array}{l}\text { Coarse } \\
\text { Nat. Agg } \\
(\mathrm{kg})\end{array}$ & $\begin{array}{l}\text { Coarse } \\
\text { Recycl. Agg } \\
(\mathrm{kg})\end{array}$ & $\begin{array}{l}\text { Super } \\
\text { plasticizer } \\
(\mathrm{kg})\end{array}$ \\
\hline NC0 & 0 & 420 & 897 & 0 & 4.87 \\
RC1 & 30 & 420 & 628 & 229 & 4.90 \\
RC2 & 50 & 420 & 449 & 381 & 5.54 \\
RC3 & 80 & 420 & 179 & 610 & 4.44 \\
RC4 & 100 & 420 & 0 & 763 & 4.96 \\
\hline
\end{tabular}

Table 3. Average mechanical properties of concrete

\begin{tabular}{llllll}
\hline Mix & $\begin{array}{l}\text { Rep } \\
(\%)\end{array}$ & $\begin{array}{c}\text { Density } \\
\left(\mathrm{kg} / \mathrm{m}^{3}\right)\end{array}$ & $\begin{array}{l}\mathrm{f}_{\mathrm{c}} \\
\left(\mathrm{N} / \mathrm{mm}^{2}\right)\end{array}$ & $\begin{array}{l}\mathrm{f}_{\mathrm{ct}} \\
\left(\mathrm{N} / \mathrm{mm}^{2}\right)\end{array}$ & $\begin{array}{l}\mathrm{E}_{\mathrm{c}} \\
\left(\mathrm{N} / \mathrm{mm}^{2}\right)\end{array}$ \\
\hline $\mathrm{NC} 0$ & 0 & 2403 & 71.1 & 4.20 & 42581 \\
$\mathrm{RC} 1$ & 30 & 2343 & 63.6 & 4.40 & 40381 \\
$\mathrm{RC} 2$ & 50 & 2329 & 62.0 & 3.94 & 37980 \\
$\mathrm{RC} 3$ & 80 & 2260 & 56.3 & 3.83 & 28818 \\
$\mathrm{RC} 4$ & 100 & 2257 & 50.8 & 3.65 & 31390 \\
\hline
\end{tabular}

\section{Experimental Results}

The experimental test was developed applying the load on the geometrical center of the slab by means of a $200 \times 200 \times 5 \mathrm{~mm}$ steel plate. The slabs were simply supported by four HEA steel beams.

At the intrados, a wire extensometer was applied in order to measure the deflection. Figure 1 presents the details of the test setup. The vertical load was applied by means of a $500 \mathrm{kN}$ hydraulic jack.

Loads and deflection has been continuously recorded. The former was increased monotonously until the punching failure of the slabs. Figure 2 shows the experimental load-deflection curves. For each mix there were 3 slabs and, consequently, 3 experimental dashed curves. The continuous black average line has also been reported.

The cracking load has been detected has the maximum value of the first linear part of each curve. It is pointed by a black spot in Fig. 2 .

The experimental cracking load and the corresponding deflection have been reported in Table 4 for each sample. In the same table there are also the average cracking load and the maximum deflection for each mix. 


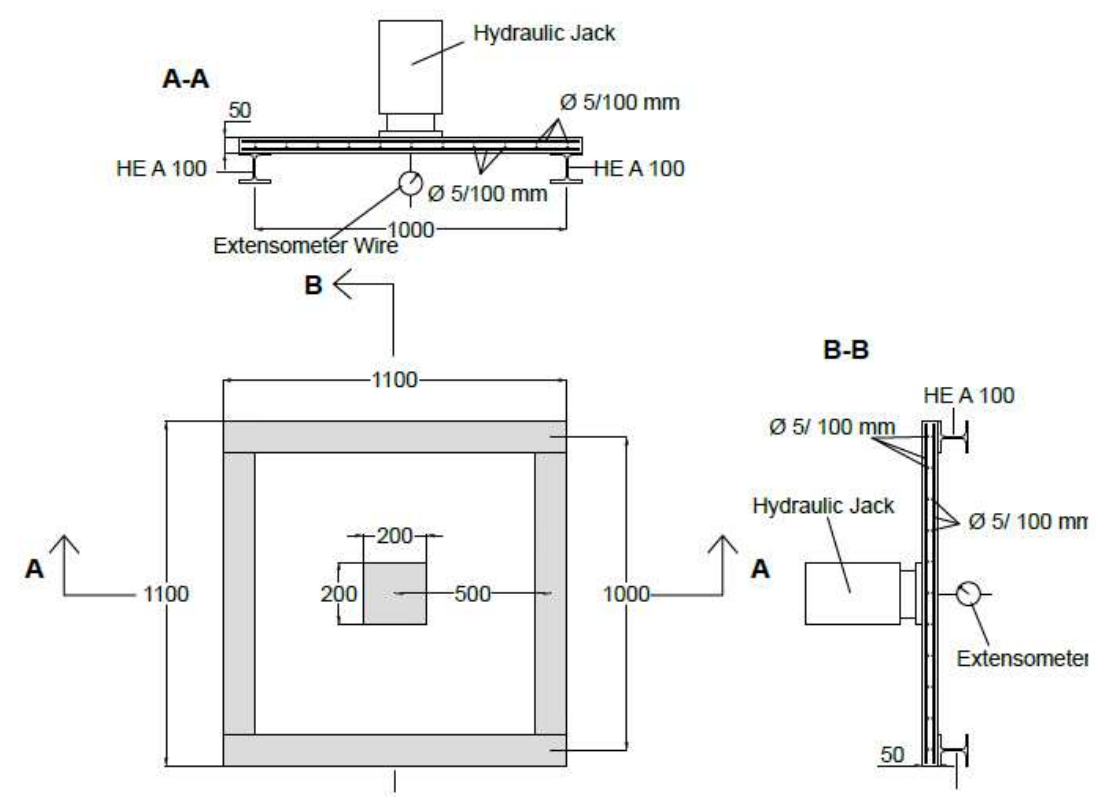

Fig. 1. Geometry of the slab specimen and test setup
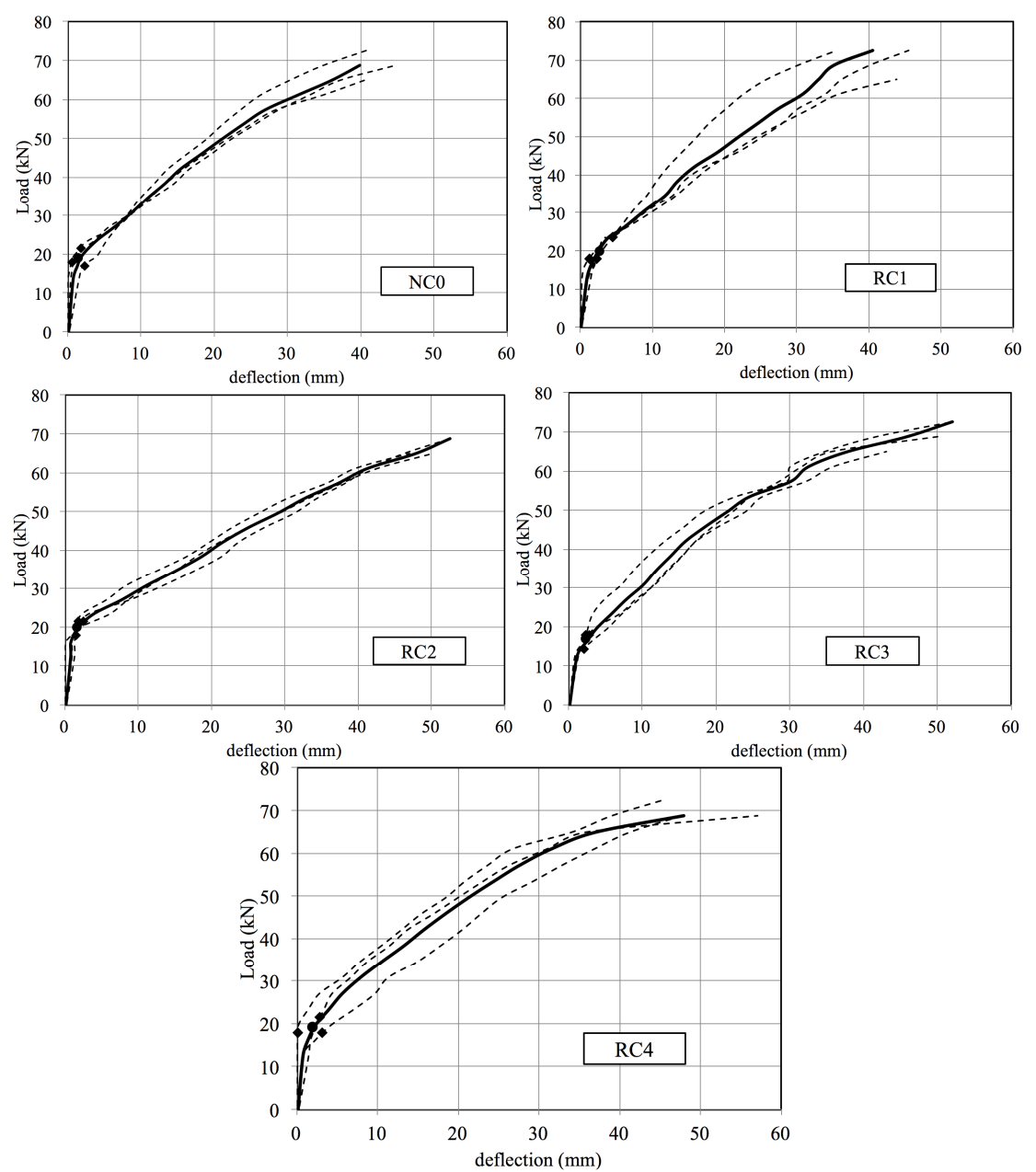

Fig. 2. Load-deflection curves of slabs 


\begin{tabular}{lllll}
\multicolumn{6}{l}{ Table 4. Defection and cracking load } \\
\hline Sample & $\begin{array}{l}\mathrm{F}_{\text {cr }} \\
(\mathrm{kN})\end{array}$ & $\begin{array}{l}\mathrm{F}_{\text {cr-average }} \\
(\mathrm{kN})\end{array}$ & $\begin{array}{l}\delta_{\text {cr }} \\
(\mathrm{mm})\end{array}$ & $\begin{array}{c}\delta_{\text {cr-max }} \\
(\mathrm{mm})\end{array}$ \\
\hline NC0-1 & 17.00 & & 2.27 & \\
NC0-2 & 21.53 & 18.80 & 1.76 & 2.27 \\
NC0-3 & 17.87 & & 0.58 & \\
RC1-1 & 17.87 & & 1.29 & \\
RC1-2 & 23.50 & 19.74 & 2.30 & 2.35 \\
RC1-3 & 17.87 & & 2.35 & \\
RC2-1 & 17.87 & & 1.54 & \\
RC2-2 & 21.53 & 20.31 & 2.49 & 2.49 \\
RC2-3 & 21.53 & & 1.82 & \\
RC3-1 & 14.23 & & 2.09 & \\
RC3-2 & 17.87 & 16.66 & 2.77 & 2.77 \\
RC3-3 & 17.87 & & 2.33 & \\
RC4-1 & 17.87 & & 3.16 & \\
RC4-2 & 21.53 & 19.09 & 2.83 & 3.16 \\
RC4-3 & 17.87 & & 0.14 & \\
\hline
\end{tabular}

\section{Theoretical Analysis}

The experimental behavior of the considered slabs is very similar to the one of a continuous slab supported by columns, in the neighborhood of a central support. The applied load represents the reaction of this central column, thus the experimental bending moment at the slab mid-span coincides with the negative bending moment in corrispondence of the central column axis.

In order to evaluate the bending moment produced by the experimental cracking load, the Equivalent Frame Method EFM was used, as reported in Chapter 13 of ACI 318 (2011) and in Appendix I of EC2 (2005)).This method leads to the elastic solution a continuous slab supported by a set of columns and characterized by a span $L_{x}$ in the $x$ direction and $L_{y}$ in the $\mathrm{y}$ direction. Considering the tested slabs dimensions the corresponding theoretical slab presents $L_{x}=L_{y}=2386$ $\mathrm{mm}$ and is subjected to a uniform load $q$. The maximum negative bending moment at the nodes of the Equivalent Frame is equal to:

$M=q \cdot L_{y} \cdot L_{x}^{2} / 12$

Considering the $L_{y} / 2$ width column strip and the two orthogonal $L_{y} / 4$ width field strips, it is possible to assume that $75 \%$ of the bending moment is related to the former one while the remaining $25 \%$ is acting on the field strips. Thus the column strip bending moment $m_{x c}$ is:

$m_{x c}=1 / 8 V \cdot L_{X} / L_{Y}$

Where:

$V=q \cdot L_{y} \cdot L_{x}$
Table 5. Theoretical cracking loads of slabs

\begin{tabular}{lll}
\hline Sample & $F_{\text {cr,theol }}(\mathrm{kN})$ & $F_{c r, \text { theo } 2}(\mathrm{kN})$ \\
\hline NC0 & 14.25 & 15.89 \\
RC1 & 14.94 & 16.25 \\
RC2 & 13.39 & 14.76 \\
RC3 & 13.10 & 13.54 \\
RC4 & 12.46 & 13.35 \\
\hline
\end{tabular}

The width of the strip can be expressed as:

$b_{s}=1.5 \cdot \sqrt{r_{s x} \cdot r_{s y}}=787.5 \mathrm{~mm}$

where, $r_{s y}, r_{s x}$ are the distances between the column axis and the points at which the radial bending moment is zero with respect the $y, x$ directions.

As said before, the reinforcement of the slab cross section is represented by a double welded layer steel mesh $100 \times 100 \mathrm{~mm}$ with $5 \mathrm{~mm}$ diameter. Thus $A_{s}=154.6$ $\mathrm{mm}^{2}$. Steel Young's modulus has been considered $E_{s}=200 \mathrm{GPa}$. Concrete compressive mechanical properties have been reported in Table 3. Concerning the tensile behaviour it was considered a two fold approach: (1) assuming $E_{c t}=E_{c}$, (2) assuming that the ultimate tensile concrete strain was $\varepsilon_{c t u}=0,00015$.T hus the elastic modulus $E_{c t}=f_{c t} / \varepsilon_{c t u}$. Therefore, a double value of the theoretical cracking moment is obtained: $m_{c r, t e h o l}$ when $E_{c t}=E_{c}$ and $m_{c r \text {, theo } 2}$ when $E_{c t}=f_{c t} / \varepsilon_{c t u}$.

Table 5 shows the theoretical cracking loads $F_{c r \text {,theol }}$ and $F_{c r}$, theo2, which can be compared to those obtained from the experimental campaign shown in Table 4.

\section{Discussion}

In case of coarse recycled aggregates, considering the experimental results reported here, the average compressive strength of the concrete, $f_{c m}\left(\mathrm{~N} / \mathrm{mm}^{2}\right)$ can be correctly estimated $\left(\mathrm{R}^{2}=0.98\right)$ from the equation:

$f_{c m}=-19 \cdot r e p \%+70$

where rep\% (aggregate replacement percentage) varies between 0 and $100 \%$.

In case of $\mathrm{rep} \%=100 \%$, the average compressive strength of the concrete presents a $29 \%$ reduction in comparison with the reference case (rep $\%=0 \%)$.

Instead, the average tensile strength of the concrete, $f_{c t m}\left(\mathrm{~N} / \mathrm{mm}^{2}\right)$ can be correctly estimated $\left(\mathrm{R}^{2}=0.74\right)$ from the equation:

$f_{c m}=-0.65 \cdot r e p \%+4.34$

In case of rep $\%=100$, the average tensile strength of the concrete presents a $13 \%$ reduction in comparison with the reference case $(\mathrm{rep} \%=0 \%)$. 


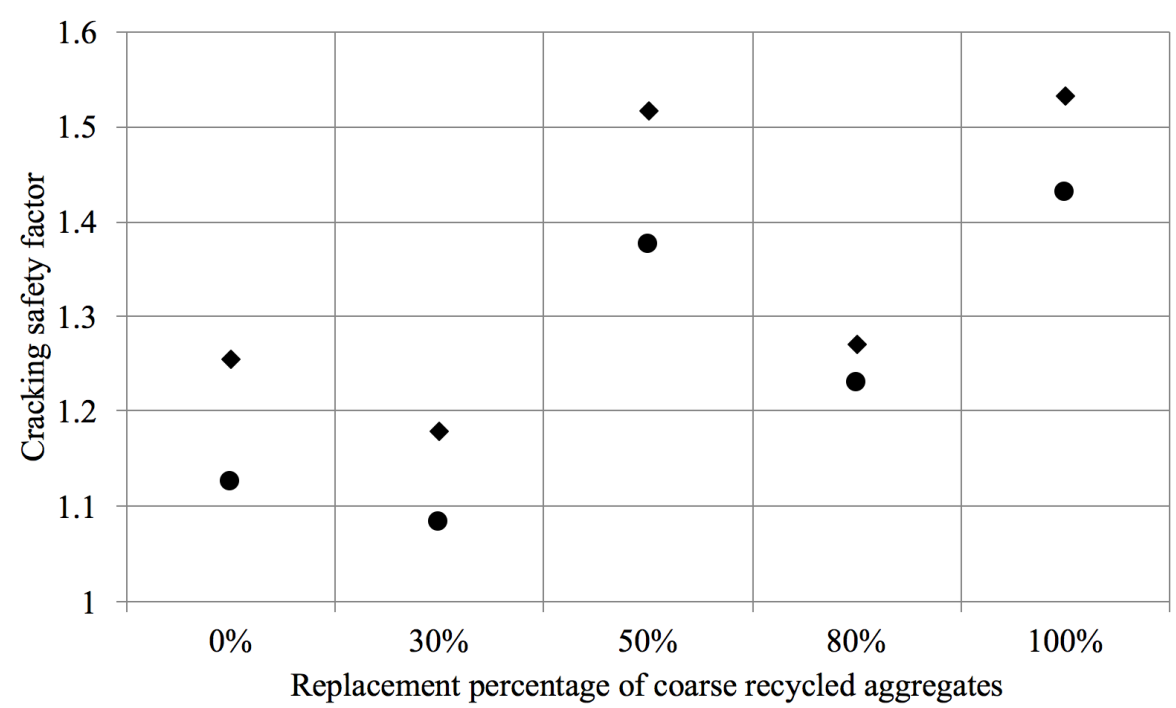

- Fcr,exp/Fcr,theo1 • Fcr,exp/ Fcr,theo2

Fig. 3. Safety factors of cracking

Table 6. Theoretical and experimental tensile strength

\begin{tabular}{llll}
\hline Sample & Rep $(\mathbf{\%})$ & $\mathrm{f}_{\text {ct,exp }}\left(\mathrm{N} / \mathrm{mm}^{2}\right)$ & $\mathrm{f}_{\text {ct, teo }}\left(\mathrm{N} / \mathrm{mm}^{2}\right)$ \\
\hline NC0 & 04 & 20 & 4.44 \\
RC1 & 30 & 4.40 & 4.22 \\
RC2 & 50 & 3.94 & 4.19 \\
RC3 & 80 & 3.83 & 3.98 \\
RC4 & 100 & 3.65 & 3.67 \\
\hline
\end{tabular}

Thus, if the tensile average strength is evaluated as a function of the compressive characteristic strength (see NTC08):

$$
\begin{aligned}
& f_{\text {cteo }}=-0.30 \cdot f_{c k} \quad C g \leq C 50 / 60 \\
& f_{\text {cteo }} 2.12 \cdot \operatorname{In}\left(1+f_{c m} / 10\right) \quad C g>C 50 / 60
\end{aligned}
$$

where, $C g$ represent the concrete grade and $f_{c m}=f_{c k+8}$. The theoretical tensile strengths are similar to the experimental ones, with maximum percentage differences of $6 \%$ regardless of the replacement percentage (see Table 6). This result shows that recycled concrete can be modeled as ordinary concrete.

The experimental average concrete young's modulus $E_{c m}$, can be represented as a function of the replacement percentage with very good accuracy $\left(\mathrm{R}^{2}=0.86\right)$ :

$$
E_{c m}=-0.1419 \cdot r e p \%+43400
$$

In case of rep $\%=100$, the average concrete Young's modulus presents a $26 \%$ reduction in comparison with the reference case $(\mathrm{rep} \%=0 \%)$.

Instead, if it is expressed as a function of the concrete average strength (see NTC08):

$$
E_{c m}=22000 \cdot\left(f_{c m} / 10\right)^{0.3}
$$

there can be assessed a quite important difference with respect the experimental values, in particular in case of rep $\%=80 \%$ and rep $\%=100 \%$ (respectively 22 and $12 \%$ ). Actually, it is known that the expression (9) represents a "weak" bond between the Young's modulus and the compressive strength. Thus, important discrepancies between expression (9) and experimental values can be expected also for concrete with natural coarse aggregate.

In the tested slabs the cracking load seems not to depend on the replacement percentage. For example, in the case rep $\%=100 \%$ the cracking load is very similar to the one corresponding to reference sample $(7 \%$ percentage difference).

The comparison between theoretical cracking load (see Table 5) and the experimental ones (Table 5) shows safety factor varying between 1.08 and 1.53 (see Fig. 3). In particular, these results show that experimental cracking loads are higher than theoretical ones (30\% percentage difference). Thus, also the durability of recycled aggregates concrete seems very promising.

\section{Conclusion}

This paper reports on the experimental investigation on flexural cracking behavior in simply supported reinforced recycled concrete slabs. The recycled concrete was made with natural aggregate and coarse recycled aggregate, produced by crushed concrete taken from authorized storage sites.

Five concrete mixes: $0 \%, 30 \%, 50 \%, 80 \%$ and $100 \%$ replacement percentage of coarse natural aggregate with 
coarse recycled aggregates have been prepared. Moreover, a comparison between theoretical analysis and experimental results have been developed. The following conclusions can be drawn.

The use of coarse recycled aggregate produces a reduction in recycled concrete performance. Compressive strength, tensile strength and modulus of elasticity decrease with increasing replacement percentage of coarse natural aggregate with coarserecycled aggregate.

The compressive strength of recycled concrete with $100 \%$ replacement percentage is reduced of $29 \%$ of the corresponding values of normal concrete.

The tensile strength of recycled concrete with 100\% replacement percentage is reduced of $13 \%$ of the corresponding values of normal concrete. The estimate of tensile strength as a function of compressive strength, through NTC2008 relationship, is very good (maximum difference $6 \%$ ) regardless of the presence of coarse recycled aggregates (even with high replacement percentage).

There is no evident reduction in the cracking load with increasing replacement percentage of coarse natural aggregate with coarse recycled aggregate. The cracking load of slab with $100 \%$ replacement percentage is higher than the corresponding value of normal concrete $(7 \%$ percentage difference). The theoretical analysis always produces cracking load safety factor values (ratio between experimental and theoretical cracking load) higher than one. In addition, this value increases with increasing replacement percentage of coarse natural aggregate with coarse recycled aggregate.

In conclusion, this paper experimentally proves that the reinforced recycled concrete slabs show good cracking performances in comparison with those realized with reinforced ordinary concrete. So the use of recycled concrete in structural elements should be encouraged also with replacement percentages higher than those established in NTC (2008).

\section{Acknowledgement}

The Authors would like to express their thanks to Italcementi Group (Sardinia, Italy) for providing natural aggregates and helping in samples making and curing and Ecoinerti - Authorized storage site (Sardinia, Italy).

\section{Funding Information}

The present work is developed within a research project supported by Regione Autonoma della Sardegna, Legge Regionale 7 agosto 2007, n. 7.

\section{Author's Contributions}

Luisa Pani and Lorena Francesconi: Developed the experimental campaigns at the Department of Civil, Environmental Engineering and Architecture University of Cagliari.

Flavio Stochino and Fausto Mistretta: Contribute to the theoretical formulation and to the paper writing.

\section{Ethics}

The Authors declare there's no conflict of interest.

\section{References}

ACI, 2001. ACI 555 R01. Removal and reuse of hardened concrete.

ACI, 2011. ACI 318. Code requirements for reinforced concrete.

Acito, M., F. Stochino and S. Tattoni, 2011. Structural response and reliability analysis of RC beam subjected to explosive loading. Applied Mechanics Materials, 82: 434-439.

BSI, 1985. BS 6543. Guide to use of industrial byproducts and waste materials in building and civil engineering.

Collins, R., 1998. Recycled Aggregates. BRE Digest 433.

De Brito, J., J. Ferreira, J. Pacheco, D. Soares and M. Guerreiro, 2016. Structural, material, mechanical and durability properties and behaviour of recycled aggregates concrete. J. Build. Engin., 6: 1-16. DOI:10.1016/j.jobe.2016.02.003

DIN, 2002. DIN 4226-100: Aggregates for Mortar and Concrete, Part 100: Recycled Aggregates. Deutsches Institut für Normung.

Etxeberria, M., A.R. Marí and E. Vázquez, 2007. Recycled aggregate concrete as structural material. Materials Structures, 40: 529-541.1 DOI: $10.1617 / \mathrm{s} 11527-006-9161-5$

European Parliament, 2011. Report from the Commission to the European Parliament, the Council, the European Economic and Social Committee and the Committee of the Regions on the Thematic Strate-gy on the Prevention and Recycling of Waste, Brussels, Belgium.

EC, 2005. Eurocode 2. Design of Concrete Structures. Part 1-1: General Rules and Rules for Buildings EN-1992-1-1.

Evangelista, L. and J. de Brito, 2007. Mechanical behavior of concrete made with fine recycled concrete aggregates. Cement Concrete Composites, 29: 397-401. DOI:10.1016/j.cemconcomp.2006.12.004

Francesconi, L, L. Pani and F. Stochino, 2016. Punching shear strength of reinforced recycled concrete slabs. Construction Building Mater., 127: 248-263. DOI: 10.1016/j.conbuildmat.2016.09.094 
Gonzalez-Fonteboa, B. and F. Martinez-Abella, 2007. Shear strength of recycled concrete beams. Construction Building Mater., 21: 887-89. DOI:10.1016/j.conbuildmat.2005.12.018

Hansen, T.C. and H. Narud, 1983. Strength of recycled concrete made from crushed concrete coarse aggregate. Concrete Int., 5: 79-83.

International Federation for Structural Concrete, 2010. Model Code 2010 Fib Bulletin N. 65 vol.1.

International Federation for Structural Concrete, 2010. Model Code 2010 Fib Bulletin N. 66 vol.2

Italian Ministry of Infrastructures and Transportation, 2008. NTC2008: Norme Tecniche per le Costruzioni D.M. 14.01.2008 (in Italian).

Levy, S.M. and P. Helene, 2004. Durability of recycled aggre-gates concrete: A safe way to sustainable development. Cement Concrete Res., 34: 1975-1980. DOI:10.1016/j.cemconres.2004.02.009

Li, X., 2008. Recycling and reuse of waste concrete in China Part I. Material behavior of recycled aggregate concrete. Resources Conservation Recycling, 53: 36-44.

DOI: 10.1016/j.resconrec.2008.09.006

Li, X., 2009. Recycling and reuse of waste concrete in China Part II. Structural behavior of recycled aggregate concrete and engineering applications. Resources Conservation Recycling, 53: 107-112. DOI:10.1016/j.resconrec.2008.11.005

Mália, M., J.de Brito, M.D. Pinheiro and M. Bravo, 2013. Construction and demolition waste indicators. Waste Management Res., 31: 241-255. DOI: $10.1177 / 0734242 X 12471707$
Pacheco, J., J. de Brito, J. Ferreira and D. Soares, 2015. Flexural load tests of full-scale recycled aggregates concrete structures. Construction Building Mater., 101:

65-71. DOI:10.1016/j.conbuildmat.2015.10.023

Poon, C.S., Z.H. Shui, L. Lam, H. Fok and S.C. Kou, 2004. Influence of moisture states of natural and recycled aggregates on the slump and compressive strength of concrete. Cement Concrete Res., 34: 31-36. DOI: 10.1016/S0008-8846(03)00186-8

Rahal, K., 2007. Mechanical properties of concrete with recycled coarse aggregate. Building Environ., 42: 407-415. DOI: 10.1016/j.buildenv.2005.07.033

Reis, N., J. de Brito, J.R. Correia and M.R.T. Arruda, 2015. Punching behaviour of concrete slabs incorporating coarse recycled concrete aggregates. Engineering Structures, 100: 238-248. DOI:10.1016/j.engstruct.2015.06.011

Stochino, F., 2016. RC beams under blast load: Reliability and sensitivity analysis. Engineering Failure Analysis, 66: 544-565. DOI: $10.1016 /$ j.engfailanal.2016.05.003

Stochino, F., F. Mistretta, P. Meloni and G. Carcangiu, 2017. Integrated approach for post-fire reinforced concrete structures assessment. Periodica Polytechnica Civil Eng. DOI: 10.3311/PPci.9830

Yang, Y.F. and L.H. Han, 2006. Experimental behavior of recycled aggregate concrete filled steel tubular columns. J. Constructional Steel Res., 62: 1310-1324. DOI:10.1016/j.jcsr.2006.02.010 